\title{
Linfoma cardíaco primário em cão
}

\section{Primary cardiac lymphoma in dog}

\author{
Letícia Abrahão Anai ${ }^{1}$; Paulo César Jark ${ }^{1 *}$; Erika Maria Terra ${ }^{1}$; Fábio Nelson Gava²; \\ Fabrício Andrade Marinho ${ }^{3}$; Sabryna Gouveia Calazans ${ }^{4}$; Mirela Tinucci Costa ${ }^{5}$; \\ Aureo Evangelista Santana ${ }^{5}$
}

\section{Resumo}

Os linfomas são neoplasias caracterizadas pela proliferação maligna de linfócitos, que originamse principalmente em órgão linfóides como linfonodos, fígado, baço e medula óssea. Entretanto pela característica de contínua migração dos linfócitos por diferentes órgãos, esta neoplasia pode se desenvolver em qualquer órgão. Embora o linfoma seja a neoplasia hematopoiética de maior incidência em cães, a localização cardíaca é rara. O diagnóstico de linfoma cardíaco primário pode ser realizado quando há envolvimento do coração e/ou pericárdio sem evidências de ocorrência de órgãos linfáticos ou extranodais. Em medicina veterinária existem poucos relatos sobre o diagnóstico, tratamento e prognóstico desta neoplasia cardíaca. Portanto o objetivo do presente relato é descrever um caso de linfoma cardíaco em que o paciente respondeu favoravelmente ao tratamento quimioterápico empregado com intervalo livre de doença de 19 meses e salientar a importância de incluir essa neoplasia na lista de diagnósticos diferenciais de doenças que acometem o sistema cardiovascular.

Palavras-chave: Linfoma, neoplasia cardíaca, quimioterapia

\begin{abstract}
Lymphomas are malignant neoplasm characterized by proliferation of lymphocytes that originate primarily in lymphoid organ such as lymph nodes, liver, spleen and bone marrow. However the feature of continuous migration of lymphocytes in different organs, this tumor can develop in any organ. Although lymphoma is a very common hematopoietic neoplasm in dogs, cardiac location is rare. The diagnosis of primary cardiac lymphoma may be performed when there is involvement of the heart and / or the pericardium without evidence of involvement in other organs. In veterinary medicine there are few reports on the diagnosis, treatment and prognosis of cardiac lymphoma. Therefore, the purpose of this report is to describe a case of cardiac lymphoma in which the patient responded favorably to chemotherapy employee with disease-free interval of 19 months and highlight the importance of including this neoplasm in the differential diagnosis of diseases that affect the cardiovascular system.
\end{abstract}

Key words: Lymphoma, cardiac neoplasm, chemotherapy

\footnotetext{
${ }^{1}$ Discente(s), Programa de Pós Graduação em Medicina Veterinária, Universidade Estadual Paulista, UNESP, Jaboticabal, SP. E-mail: letanai@hotmail.com; paulocjark@hotmail.com; erikamterra@hotmail.com

2 Prof. da Universidade Camilo Castelo Branco, UNICASTELO, Descalvado, SP. E-mail: fabiongava@yahoo.com.br

${ }^{3}$ Discente, Programa de Pós Graduação em Medicina Veterinária, UNESP, Jaboticabal, SP. E-mail: fabriciomarinho@hotmail.com

${ }^{4}$ Prof ${ }^{a}$. da Universidade de Franca/Instituto Bioethicus, Franca, Botucatu. E-mail: sgcalazans@gmail.com

${ }^{5}$ Profs. do Dept ${ }^{\circ}$ de Clínica e Cirurgia Veterinária, UNESP, Jaboticabal, SP. E-mail: mirelatc@fcav.unesp.br; santana@fcav.unesp.br

* Autor para correspondência
} 


\section{Introdução}

Linfomas são neoplasias caracterizadas pela proliferação maligna de linfócitos, que originamse principalmente em órgão linfóides como linfonodos, fígado, baço e medula óssea. Entretanto pela característica de contínua migração dos linfócitos por diferentes órgãos, esta neoplasia pode se desenvolver em qualquer órgão (DALECK; CALAZANS; DENARDI, 2008).

Embora o linfoma seja a neoplasia hematopoiética de maior incidência em cães, a localização cardíaca é rara (SIMS et al., 2003). Em humanos os linfomas cardíacos compreendem menos de $2 \%$ das neoplasias cardíacas primárias e menos de $1 \%$ dos linfomas extranodais (BAGWAN et al., 2009).

Os linfomas cardíacos em humanos geralmente apresentam evolução rápida e o prognóstico é desfavorável na maioria dos casos (SIMS et al., 2003). Em medicina veterinária pelo fato de ser uma neoplasia rara, existem poucos estudos sobre o diagnóstico, tratamento e prognóstico desta neoplasia cardíaca (SIMS et al., 2003; MACGREGOR et al., 2005). Portanto o objetivo do presente relato é descrever um caso de linfoma cardíaco em um cão que respondeu favoravelmente ao protocolo quimioterápico empregado.

\section{Relato de Caso}

Um cão, fêmea castrada, sem raça definida, de 8 anos de idade, pesando $28 \mathrm{~kg}$, foi atendido no Hospital Veterinário "Governador Laudo Natel" da Faculdade de Ciências Agrárias e Veterinárias UNESP- Jaboticabal com histórico de aumento de volume abdominal, apatia, hiporexia, emagrecimento progressivo, cansaço fácil e dispneia discreta com 7 dias de evolução. Durante o exame físico foram observados abaulamento abdominal com presença de líquido livre e hipofonese de bulhas cardíacas na auscultação cardiopulmonar. Os demais exames estavam dentro dos padrões de normalidade.

$\mathrm{O}$ animal foi submetido ao ecocardiograma (Figura 1) que revelou quantidade acentuada de efusão pericárdica, câmaras cardíacas e válvulas sem alterações e ausência de efusão pleural. O eletrocardiograma revelou ritmo sinusal e supressão de milivoltagem de onda $\mathrm{R}$, compatível com a efusão pericárdica.

Figura 1. Imagem ecocardiográfica destacando massa hiperecogênica em miocárdio de ventrículo direito e presença de efusão pericárdica.

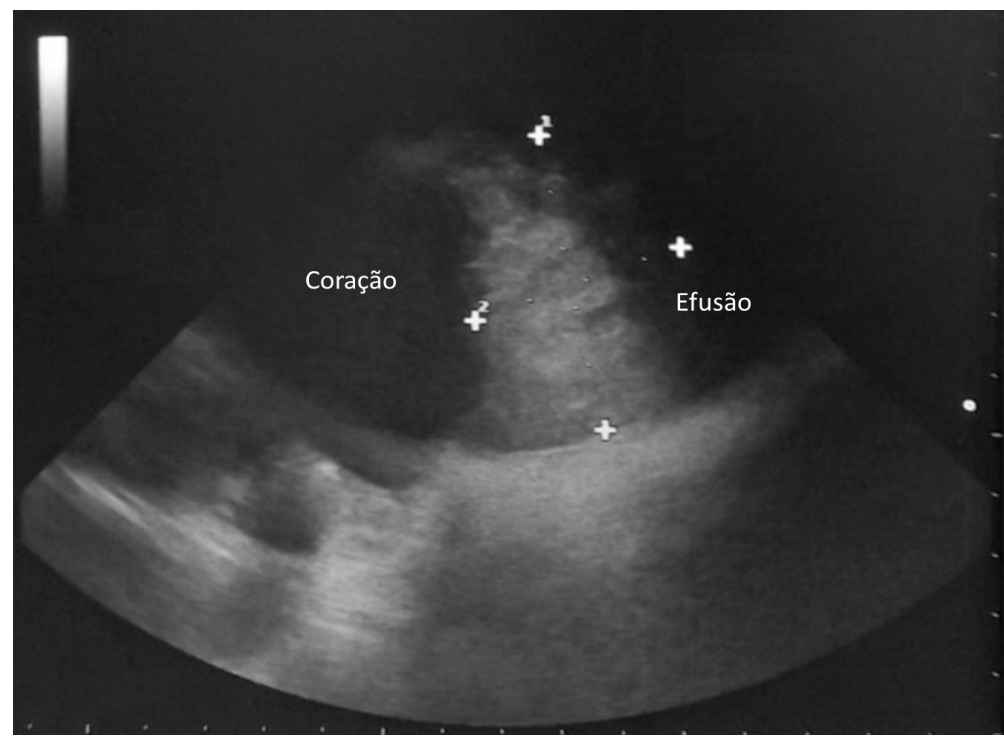

Fonte: Elaboração dos autores. 
A pericardiocentese foi realizada no hemitórax direito, após tricotomia e anti-sepsia e anestesia local com lidocaína 2\%. O animal foi posicionado em decúbito esternal e monitorado através de eletrocardiograma. Utilizou-se cateter $\mathrm{n}^{\circ} 16$ no $5^{\circ}$ espaço intercostal direito, conectado a um equipo, torneira de três vias e seringa. Foram drenados 60 $\mathrm{ml}$ de efusão com aspecto sanguinolento, a qual foi enviada para avaliação citológica.

Na preparação citoscópica da efusão pericárdica, notaram-se presença de hemácias permeadas por um componente celular mononucleado de origem linfoide, com elevado grau de pleomorfismo e com critérios cariocitoplasmáticos de anisocitose, anisocariose, vacuolização citoplasmática, índice mitótico alto e nucléolos proeminentes, compatível com um quadro de linfoma (Figura 2). Foi realizada análise da efusão abdominal, porém não foram evidenciadas células neoplásicas. A ultrassonografia abdominal não apresentava sinais de envolvimento em outros órgãos.

Figura 2. Citologia de efusão pericárdica, com presença de linfócitos atípicos e varias figuras de mitose em cão. Aumento 1000x, coloração: mistura de Metanol, May-Grunwald e Giemsa - MGG. Laboratório de Patologia Clínica Veterinária, do Hospital Veterinário "Governandor Laudo Natel”.

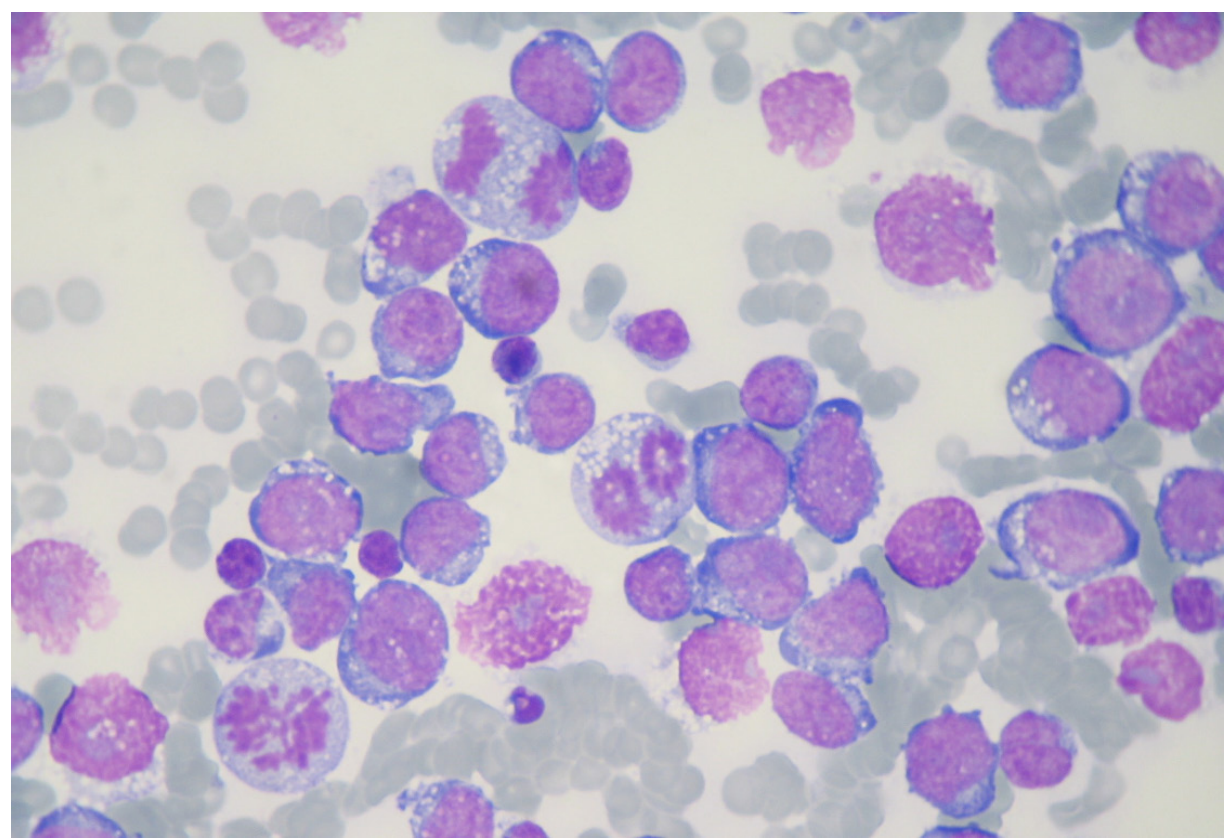

Fonte: Elaboração dos autores.

Após a confirmação do diagnóstico através da citologia, o animal foi submetido ao protocolo quimioterápico Madison Wisconsin (Vincristina, Ciclofosfamida, Doxorrubicina, Prednisona). O animal apresentou melhora significativa após o inicio da quimioterapia, com resolução dos sinais clínicos. Porém até a terceira semana do tratamento quimioterápico, o paciente ainda apresentava efusão pericárdica sendo necessária a realização de pericardiocenteses semanais.

Após a quarta semana de tratamento quimioterápico, o animal não apresentou mais sinais ecocardiográficos de efusão pericárdica, apresentava bom estado geral, sem sinais clínicos da doença sendo considerado em remissão completa. Após 25 semanas de tratamento, o paciente terminou 
o protocolo inicialmente proposto, porém devido a possibilidade de recidiva da doença foi sugerido manter o animal em tratamento, com intervalos de 21 dias entre as sessões de quimioterapia e substituindo a doxorrubicina por actinomicina -D devido aos riscos de desenvolvimento de cardiomiopatia dilatada secundária ao tratamento com a doxorrubicina, pois o animal apresentou diminuição da fração de encurtamento pelo exame ecocardiográfico. $\mathrm{Na} 66^{\circ}$ semana do protocolo, o proprietário optou por suspender a quimioterapia devido aos custos com o tratamento e foi sugerido acompanhamento mensal através de exames ecocardiográficos. Até o momento o animal encontra-se em remissão completa da doença, com tempo livre de doença de 19 meses.

\section{Discussão e Conclusão}

Neoplasias acometendo o pericárdio, miocárdio ou a base cardíaca são infrequentes em cães (WARE; HOPPER, 1999). O tumor cardíaco primário de maior incidência nesta espécie é o hemangiossarcoma, seguido pelos tumores de base de coração como o quimiodectoma (WARE; HOPPER, 1999). Embora o linfoma seja uma neoplasia frequente em cães, raramente esta neoplasia acomete primariamente $\mathrm{o}$ coração (SIMS et al., 2003). Em um levantamento de 1.383 casos de tumores cardíacos em cães, apenas 34 foram diagnosticados como linfomas cardíacos (WARE; HOPPER, 1999).

O diagnóstico de linfoma cardíaco primário é realizado quando há envolvimento do coração e/ ou pericárdio sem evidências de envolvimento de órgãos linfáticos ou extranodais, como o descrito no presente caso. O paciente não apresentava envolvimento de linfonodos periféricos, na análise do liquido ascítico não foram evidenciadas células neoplásicas e a ultrassonografia abdominal não apresentava sinais de envolvimento em outros órgãos. (BAGWAN et al., 2009)

Em humanos a frequência de linfomas, incluindo os de localização cardíaca, são maiores em pacientes com vírus da imunodeficiência ou outras causas de imunossupressão, porém em cães não há evidência de uma participação viral no desenvolvimento de linfomas e o paciente não apresentava nenhum sinal de imunossupressão (SIMS et al., 2003).

Os sinais clínicos de cansaço fácil, dispneia, emagrecimento progressivo e ascite apresentados pelo animal são consistentes com manifestações clínicas comuns apresentadas em diversas doenças que acometem o sistema cardiovascular. Desta forma a presença de efusão pericárdica e a análise citológica da mesma foram fundamentais para o correto diagnóstico. As principais causas de efusão pericárdica em cães são doenças neoplásicas seguidas de pericardites idiopáticas (JOHNSON et al., 2004). Entre as efusões de origem neoplásicas as três principais causas são hemangiossarcoma, quimiodectoma e mesotelioma, sendo a efusão neoplásica secundária a linfoma rara, ocorrendo em apenas dois cães em um estudo que avaliou 164 casos de efusão pericárdicas (MACGREGOR et al., 2005). Outras causas, que poderiam ser incluídas no diagnóstico diferencial deste caso são as efusões pericárdicas secundárias a infecções fúngicas, bacterianas, corpos estranhos intrapericárdicos e coagulopatias (SIMS et al., 2003; BAGWAN et al., 2009).

A pericardiocentese realizada no paciente é um procedimento importante tanto para a coleta de material para análise citológica do líquido como para o alívio dos sinais clínicos causados pelo tamponamento cardíaco (JOHNSON et al., 2004). A combinação do protocolo quimioterápico empregado é considerado um dos mais efetivos no tratamento de linfoma em cães (MACGREGOR et al., 2005; CHUN, 2009).

A Organização Mundial da Saúde classifica o linfoma de acordo com o estágio (extensão da doença) e substágios (presença ou não de sinais clínicos relacionados ao quadro). Por este critério, os linfomas cardíacos com efusão pericárdica são classificados em estágio V (localização extranodal) e substágio b 
(presença de sinais clínicos) (MACGREGOR et al., 2005). Pacientes com linfoma em estágio III, IV ou V e substágio b, como o animal relatado, apresentam pior prognóstico, porém neste caso o animal pode ser considerado uma exceção, devido ao período livre de doença que esta apresentando.

Em um trabalho que avaliou o prognóstico de 12 cães com linfoma cardíaco, a média de sobrevida dos pacientes que não receberam quimioterapia foi de 22 dias e dos animais tratados com quimioterapia foi de 157 dias, com alguns cães apresentando tempo de sobrevida longo (MACGREGOR et al., 2005). O paciente até o momento apresenta-se em remissão total, com tempo livre de doença de 19 meses.

Apesar de o linfoma cardíaco ser uma neoplasiarara e os linfomas extranodais geralmente apresentarem comportamento mais agressivo, o presente relato demonstrou que o prognóstico pode ser favorável, quando empregada quimioterapia adequada.

\section{Referências}

BAGWAN, I. N.; DESAI, S.; WOTHERSPOON, A.; SHEPPARD, M. N. Unusual presentationof primary cardiac lymphoma. Interactive Cardiovascular and Thoracic Surgery, London, v. 9, n. 1, p. 127-129, 2009.

CHUN, R. Lymphoma: which chemotherapy protocol and why? Topics in Companion Animal Medicine, Madison, v. 24, n. 3, p. 157-161, 2009.

DALECK, C. R.; CALAZANS, S. G.; DENARDI, A. B. Linfomas. In: DALECK, C. R.; DENARDI, A. B.; RODASKI, S. Oncologia em cães e gatos. São Paulo: Roca, 2008. p. 482-505.

JOHNSON, M. S.; MARTIN, M.; BINNS, S.; DAY, M. $\mathrm{J}$. A retrospective study of clinical findings, treatment and outcome in 143 dogs with pericardial effusion. Journal of Small Animal Practice, Oxford, v. 45, n. 11, p. 546-552, 2004.

MACGREGOR, J. M.; FARIA, M. L.; MOORE, A. S.; TOBIAS, A. H.; BROWN, D. J.; DEMORAIS, H. S. Cardiac lymphoma and pericardial effusion in dogs: 12 cases (1994-2004). Journal of American Veterinary Medical Association, Illinois, v. 9, n. 9, p. 1449-1453, 2005.

SIMS, C. S.; TOBIAS, A. H.; HAYDEN, D. W.; FINE, D. M.; BORJESSON, D. L.; AIRD, B. Pericardial effusion due primary cardiac lymphosarcoma in a dog. Journal of Veterinary Internal Medicine, United Kingdom, v. 17, n. 6, p. 923-927, 2003.

WARE, W. A.; HOPPER, D. L. Cardiac tumors in dogs: 1982-1995. Journal of Veterinary Internal Medicine, United Kingdom, v. 13, n. 2, p. 95-103, 1999. 
